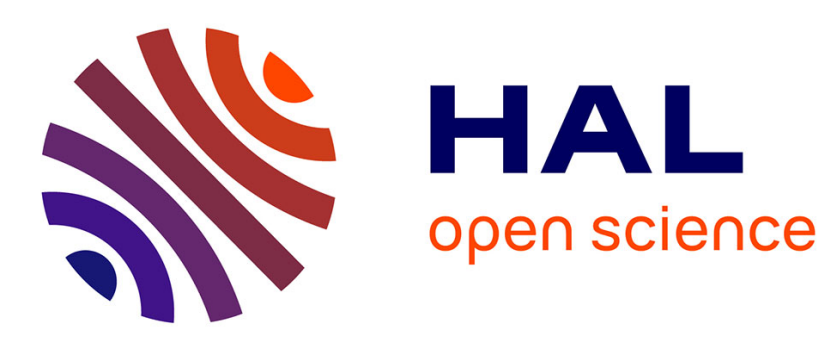

\title{
A propos de l'éclaircie par le haut et arbres d'avenir F. de Pourtalès
}

\section{To cite this version:}

F. de Pourtalès. A propos de l'éclaircie par le haut et arbres d'avenir. 1992, pp.95-96. $10.4267 / 2042 / 26302$. hal-03444108

\section{HAL Id: hal-03444108 \\ https://hal.science/hal-03444108}

Submitted on 23 Nov 2021

HAL is a multi-disciplinary open access archive for the deposit and dissemination of scientific research documents, whether they are published or not. The documents may come from teaching and research institutions in France or abroad, or from public or private research centers.
L'archive ouverte pluridisciplinaire HAL, est destinée au dépôt et à la diffusion de documents scientifiques de niveau recherche, publiés ou non, émanant des établissements d'enseignement et de recherche français ou étrangers, des laboratoires publics ou privés. 


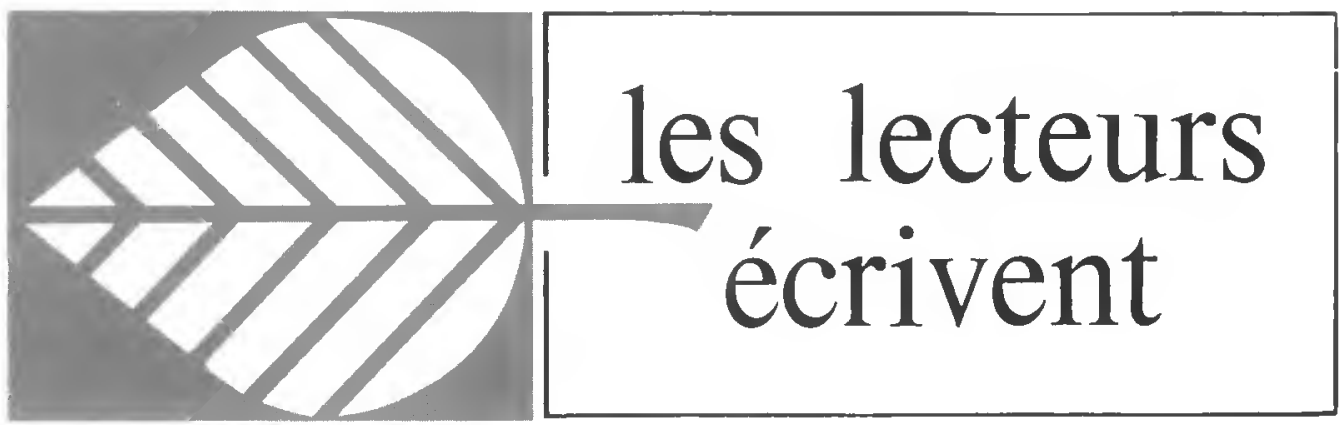

\section{À PROPOS DE L'ÉCLAIRCIE PAR LE HAUT ET ARBRES D'AVENIR}

L'article de Monsieur le Professeur R. Schober traitant de l's éclaircie par le haut et arbres d'avenir " (paru dans le $n^{\circ} 5 / 1991$ de la Revue forestière française) a éveillé toute mon attention et je dirai d'emblée que je me permets de partager entièrement les observations qui y sont décrites et pourtant, j'aimerais y apporter les remarques suivantes.

II y a une différence fondamentale entre un peuplement suivi par des chercheurs et un autre traité, soit à la tâche soit en régie, par des forestiers-bûcherons dans le cadre des travaux de soins aux jeunes peuplements (moyens financiers annuels très limités) : c'est la différence entre les rosiers de mon jardin, que ma femme suit journellement avec attention, et les rosiers que le jardinier cultive en plein champs pour les planter dans les jardins de ses clients.

Depuis vingt-deux ans, j'enseigne la sylviculture et son application pratique à l'École intercantonale de gardes forestiers de Lyss en Suisse. Chaque année, nous traitons pratiquement, au cours de nos exercices, 10 à 20 ha de fourrés et de perchis. En observant les grands retards, un peu partout dans le pays, dans les traitements des jeunes peuplements, il a bien fallu se poser la question: "faut-il concentrer les moyens limités des entreprises forestières sur une petite surface ou vaut-il mieux traiter de plus grandes surfaces en prenant le risque limité de la modification du statut social ou qualitatif de certains arbres d'un peuplement au fil des années?". Nous avons opté pour le risque limité et les grandes surfaces à traiter car, dans notre pays, la destruction de jeunes peuplements par les méfaits de la neige lourde est notablement plus préjudiciable que la modification du statut.

En deux mots :

- nous repérons tous les arbres "candidats" d'un peuplement et nous les ceinturons d'une banderole de couleur:

- nous cherchons parmi ces "candidats" ceux qui se rapprochent le plus possible d'un réseau triangulaire idéal (équidistance $=$ diamètre des couronnes adultes), nous les ceinturons d'une seconde banderole;

- nous repérons leurs concurrents immédiats et nous les abattons ;

- au milieu du triangle formé par les "candidats", nous dégageons de la même manière un remplaçant éventuel. 
Si le retard dans l'entreprise forestière est important, nous passons au peuplement suivant. Si le rythme des traitements correspond aux nécessités des peuplements et que les moyens dont dispose l'entreprise sont suffisants, nous soignons aussi le peuplement auxiliaire et nous procédons à l'élagage des "candidats".

Cette manière de procéder a l'avantage de mettre en évidence les arbres "à respecter " lors des travaux futurs et diminue les dégâts d'abattage et de débardage. Concernant les dégâts constatés par le rapport auquel il est fait allusion dans l'article (p. 387, "d'après les Suisses "), il s'agit de peuplements où la réduction du nombre de tiges a été opérée beaucoup trop tardivement. II faut intervenir tôt et si possible avec la serpe (croissant) : économie d'efforts et de temps et surtout sauvetage du peuplement auxiliaire nécessaire à l'éducation des " candidats $»$.

F. de POURTALÈS

ingénieur forestier

ÉCOLE INTERCANTONALE

DE GARDES FORESTIERS LYSS

Rossiweg 9

$\mathrm{CH}-3250$ LYSS

\section{À PROPOS DE LA SCHLITTE}

"Nous avons beaucoup apprécié l'étude, écrite il y a 100 ans, sur la schlitte et ses chemins, reproduite dans le $n^{\circ} 3 / 1991$ de la Revue forestière française.

D'autres textes - plus récents! - valent aussi qu'on s'y reporte, le cas échéant, et notamment :

- BRIGNON (M.). - Le Schlittage dans les Vosges. - L'Essor, revue des ACCS, Schirmeck, 1980-1981:

- Présentation générale. Le schlittage au bouc, $n^{\circ} 106$, pp. 2-10.

- Le schlittage sur ravetons. Le schlittage au couple bouc/chèvre, $n^{\circ} 107, p p .6-12$.

- Le schlittage du bois de chauffage, $n^{\circ} 108-109, p p .19-25$.

- Le schlittage "à bête ", $n^{\circ} 110, p p .10-16$.

- NOËL (M.), BOCQUET (A.). - Les Hommes et le bois, histoire et technologie du bois de la préhistoire à nos jours. - Paris: Hachette, 1977. - 347 pages.

Nous sommes toujours intéressé par les publications parues sur la schlitte et les utilisations techniques.

Merci par avance aux lecteurs de la Revue forestière française qui voudront bien nous en indiquer".

\section{NOËL \\ Chercheur CNRS}

FACULTÉ DE DROIT ET DES SCIENCES ÉCONOMIQUES

39, rue de I'Université 34060 MONTPELLIER CÉDEX 